\title{
Short-Term Core Strengthening Program Improves Functional Movement Score in Untrained College Students
}

\author{
Tijana Šćepanović ${ }^{1}$, Branka Protić-Gava ${ }^{1}$, , Goran Sporiš ${ }^{2}$, Tomislav Rupčić ${ }^{2}$, \\ Zvonko Miljković ${ }^{3}$, Konstantinos Liapikos ${ }^{4}$, Draženka Mačak ${ }^{1, *}$, Dejan M. Madić ${ }^{1}$ (i) \\ and Nebojša Trajković ${ }^{1}$ \\ 1 Faculty of Sport and Physical Education, University of Novi Sad, 21000 Novi Sad, Serbia; \\ tijanascepanovic021@gmail.com (T.Š.); brankapg@gmail.com (B.P.-G.); \\ dekimadic@gmail.com (D.M.M.); nele_trajce@yahoo.com (N.T.) \\ 2 Faculty of Kinesiology, University of Zagreb, 10000 Zagreb, Croatia; goran.sporis@kif.unizg.hr (G.S.); \\ tomislav.rupcic@kif.unizg.hr (T.R.) \\ 3 Faculty of Mechanical Engineering, University of Osijek, 35000 Slavonski Brod, Croatia; \\ apartmanmiljkovica@gmail.com \\ 4 Primary School of Demenika, 26000 Patras, Greece; kliapikos@yahoo.gr \\ * Correspondence: macak.md@yahoo.com; Tel.: +381-62-819-5716
}

Received: 23 October 2020; Accepted: 20 November 2020; Published: 22 November 2020

\begin{abstract}
Functional movement is an important part of developing athletes' but also untrained individuals' performance. Its monitoring also proved useful in identifying functional limitations and asymmetries, and also in determining the intervention effects. The quasi-experimental pre-test post-test study investigated the effects of core stability training program on the Functional Movement Screen (FMS) score in untrained students after six weeks. The intervention (INT) and control (CG) groups included 73 and 65 male students, respectively. Functional movement patterns were evaluated using the FMS including seven components scores representing seven basic functional patterns. Both groups significantly improved almost all FMS components scores, but the INT increased the mean performance of the hurdle step (partial $\eta^{2} \times 100=4 \%, p=0.02$ ), in-line lunge (partial $\eta^{2} \times 100=3 \%$, $p=0.05$ ), rotatory stability (partial $\eta^{2} \times 100=4 \%, p=0.02$ ) and total FMS (partial $\eta^{2} \times 100=3 \%$, $p=0.04)$ significantly more than the CG. This justifies that core strengthening can improve FMS in untrained individuals even with the short duration programs.
\end{abstract}

Keywords: functional movement screen; injury prevention; core strength; stability training; students

\section{Introduction}

There is a clear evidence that a sedentary lifestyle, low physical fitness and levels of physical activity represent risk factors for musculoskeletal injuries [1]. Health benefits of physical activities mainly depend on engagement at recommended levels [2]. Accordingly, there are great number of activity-induced injuries among young adults [3,4].

Despite possible limitations in determining the risk factors for injuries, some screening measures have demonstrated promise in various populations [5]. Traditional tests for evaluation of strength or range of motion cannot detect fundamental changes in motor control [6]. However, the Functional Movement Screen (FMS) aims to identify imbalances in mobility and stability during seven fundamental movement patterns [7]. Although the FMS is primarily designed to screen active adults for future injury, determining a baseline of movement competence could allow comparisons after treatment or rehabilitation [5]. 
Previous studies have examined the effects of various training interventions on the FMS in different groups of participants where short-term functional movement training was not enough to improve the FMS performance in adolescents [8]. Additionally, individually based specific mobility and neuromuscular control training did not elicit positive changes in the FMS scores in firefighters after 12 weeks [9]. However, the improvements in the FMS scores were shown after a six-weeks training program in children [10], a yoga program [11], and a six-week functional training program [12]. At higher competitive levels in professional American football players, the improvements in the FMS scores were also collected after a seven-week corrective exercise program [6].

Core stability has been considered as a decisive factor in foundation for movement of the extremities, for supporting loads, and for the protection of the spinal cord and nerve roots [13]. It has also been speculated that inadequate static core stability may compromise the dynamic stability of the extremities, which could lead to increased stress on the soft tissue [14,15], and the appearance of repetitive strain injuries [16].

Improved postural stability and increased core endurance has been shown in university students following an eight-week thoracic spine stabilization exercise program [17]. It has been stated that core training emphasizes strength and conditioning of the local and global muscles that work together to stabilize the spine [16]. Accordingly, a significant improvement was found in the back-endurance tests after a 10-week stability ball core training program [18]. Similarly, positive effects from a spinal stability exercise protocol using Swiss balls was winkled out in sedentary people [19].

The benefits of FMS in injury prediction have been documented [5]. However, injuries are not just characteristic of athletes. Therefore, identifying weaknesses in healthy adults and then trying to improve it could play a significant role for lifelong physical activity and movement [20]. Moreover, it was demonstrated recently that FMS performance has a strong association with key health markers [21]. Therefore, the aim of the present study was to investigate the effects of core stability training program on the FMS scores in young untrained adults. It was hypothesized that core strengthening training would improve the FMS of students.

\section{Materials and Methods}

A quasi-experimental, pre-test/post-test control group design was used in this study. University students from Novi Sad, Serbia volunteered to participate and were placed into one of two groups: intervention and control group. The intervention consisted of the implementation of a core exercise program three times per week. The FMS scores were examined before and after a six-week training intervention. Participants were tested for changes in basic patterns of movement that were measured by Cook's FMS [7]. All participants were asked to continue their standard obligations at the faculty and to refrain from making any changes to their physical activity habits for the six-week period.

\subsection{Participants}

A total of 138 males were divided into two groups, intervention (INT) (mean \pm SD: $\mathrm{n}=73$, age $20 \pm 0.5$ years, height $180 \pm 5.20 \mathrm{~cm}$, body mass $76 \pm 9.4 \mathrm{~kg})$, and control $(\mathrm{CG})(\mathrm{n}=65$, age $20 \pm 0.7$ years, height $181 \pm 8.10 \mathrm{~cm}$, body mass $78.6 \pm 4.7 \mathrm{~kg}$ ). We included healthy subjects who were not engaged in any systematic training in the last two years, but they had systematically practiced a sport for at least three years. Participants were free of any musculoskeletal injury or illness. University ethics board approved the study (ref. no. 20/2018), and all the participants gave their informed consent before any data collection. Testing procedures were performed following the ethical standards laid down in the Declaration of Helsinki. Figure 1 presents flow diagram for study participants. 


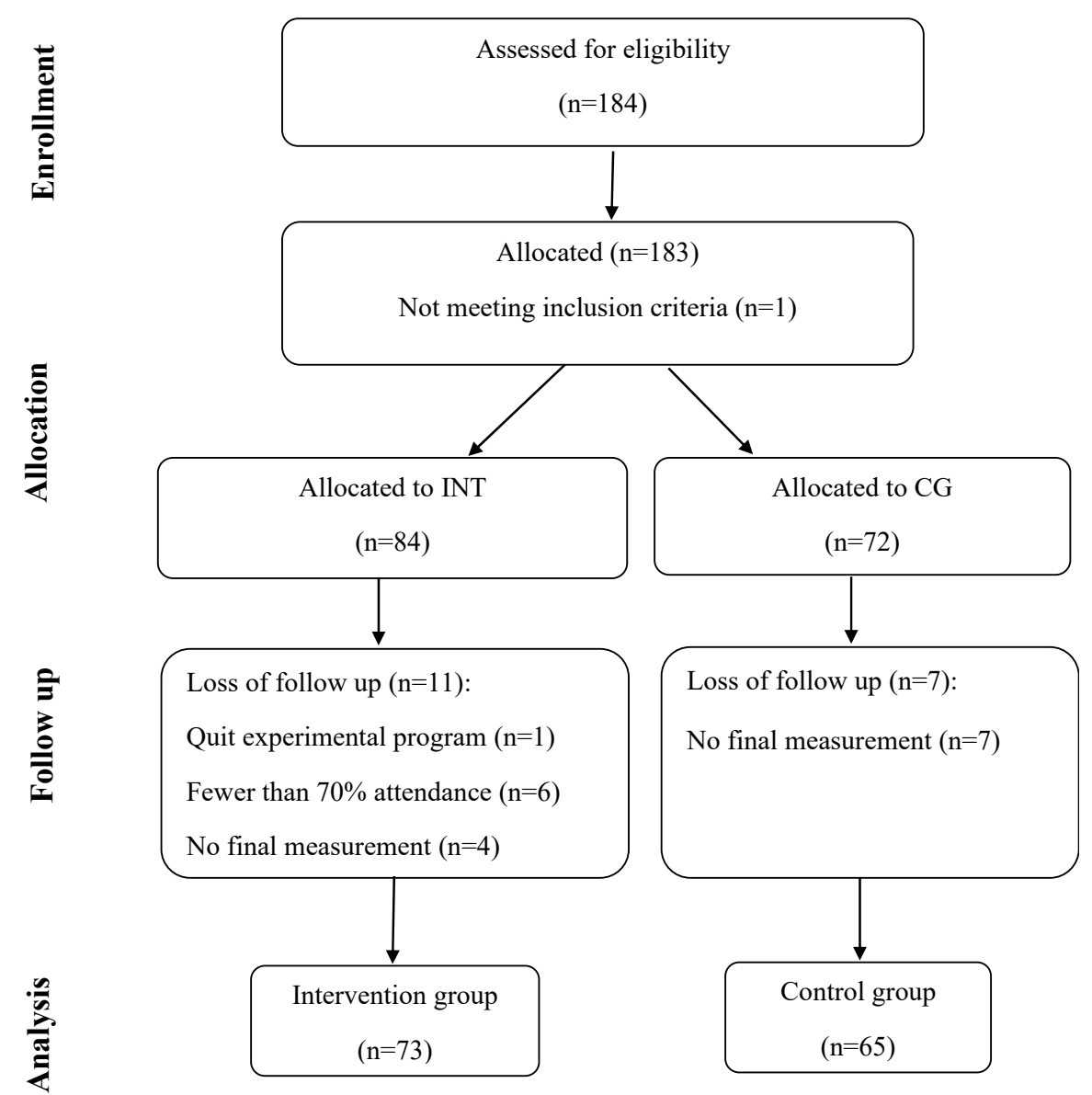

Figure 1. Flow diagram of participant enrolment, group allocation and final analysis.

\subsection{Testing Procedures}

Functional movement patterns were evaluated using the FMS [22]. The FMS identifies limits in seven basic functional patterns: deep squat, hurdle step, in-line lunge, shoulder mobility, active straight leg raises, trunk stability push-up and rotary stability. Reliability of FMS was confirmed in previous studies [23,24].

Testing was performed using a model of score from 0-3 [22]. The zero score was given to the respondents who felt pain during the tests. In cases when they felt pain, regardless if the task had been executed or not, they did not pass the test. Score one was given to the respondents who did not do the test by following given instructions. Score two indicated that the respondent could carry out the given movement, but there was a lower degree of limitation or compensation for the movement. Score three was given to the respondents who performed the movement in the described way, without any compensation. The overall score of the screening represented the sum of individual assessments of each test, totaling 21. Five of seven tests were bilaterally tested, meaning both for the left and right body side individually. In the case of bilateral tests, when the respondent received a lower score for one body side, that score was taken as an overall score for that specific test.

Initial testing was conducted in October and the final testing was conducted in December. All subjects were tested during the semester, with subject testing occurring at the start of the day, just before the lessons. A familiarization day supervised by a certified strength and conditioning specialist was implemented a week prior to conducting the baseline tests to ensure that the participants understood the testing procedures and to demonstrate reliability in testing measures.

The FMS was recorded using two video cameras (Panasonic, NV-GS400, Panasonic Corp., Osaka, Japan) placed in the frontal and sagittal planes and scored later. Two raters, both of whom 
had two years of experience using the FMS in clinical practice, scored participant performance on the movement tasks. A subgroup analysis showed good interrater reliability between the raters for composite scoring (intraclass correlation coefficient, 0.897).

\subsection{Program}

Participants were required to take part in a six-week program which included supervised sessions three times per week with sessions lasting 30 min each. Core strengthening program involved an isometric exercise program, sustained contraction against an immovable load or resistance with no or minimal change in length of the involved muscle group [10] and was implemented in the first and second week. The exercises were focused on the weakest and asymmetrical scores, with primary focus on mobility patterns and secondary focus onto stability patterns. Most of the exercises included activities where the upper extremity and the lower extremity were active at the same time while holding a neutral abdominal posture. Exercises of anti-flexion, anti-extension and anti-rotation were used to stabilize the spine. The treatment included exercises for increasing the mobility and strength of the neck, shoulders, pelvis and hips. In the first two weeks, participants did various durability exercises (all position planks, plank walk, plank jacks, forearm to pushup plank, etc.). The third and fourth week included similar exercises reinforced with additional movements and rotations (alternating arm and leg plank hold, superman plank hold, front plank plate switches, etc.). During the fifth and sixth week, the exercises were performed on unstable surfaces (Table 1). The McGill curl up [25], performed by flexing torso in the supine position with elbows on the floor, was performed during every treatment for all six weeks.

Table 1. Core strengthening program.

\begin{tabular}{|c|c|c|}
\hline Week & Exercises & Sets, Reps, Time \\
\hline $1-2$ & $\begin{array}{c}\text { All position planks (pushup, forearm, side, reverse) } \\
\text { Plank walk } \\
\text { Plank jacks } \\
\text { Forearm to pushup plank } \\
\text { Feet elevated side plank } \\
\text { 3-point plank } \\
\text { Bird dog }\end{array}$ & Hold (average) $50 \mathrm{~s}$ \\
\hline $3-4$ & $\begin{array}{l}\text { Alternating arm plank hold } \\
\text { Alternating leg plank hold } \\
\text { Superman plank hold } \\
\text { Side plank star hold } \\
\text { Alligator plank walk } \\
\text { Plank barrel roll } \\
\text { Bird dog }\end{array}$ & 20-30 reps \\
\hline $5-6$ & $\begin{array}{l}\text { Plank down dog to toe tap } \\
\text { Plank with single arm fly, feet on ball } \\
\text { Feet elevated side plank } \\
\text { Side plank hip adduction circle } \\
\text { Front plank plate switches } \\
\text { Side plank raises on ball } \\
\text { Swiss-ball stir the pot } \\
\text { Bird dog }\end{array}$ & 20-30 reps \\
\hline $1-6$ & McGill curl up & 20 reps \\
\hline
\end{tabular}

Both groups were not involved in any systematic exercise training except a regular program at the Faculty of Sports. The program represents a group of activities carried out at the Faculty of Sports during the second year. The sports activities represented in the regular classes were football, handball and rhythmic gymnastics. Respondents learned only techniques in the listed sports. 


\subsection{Statistical Analysis}

Data were analyzed using SPSS (version 20.0, IBM Corp., Armonk, NY, USA). Mean and standard deviations for the pre- and post-test FMS scores were calculated for each group. Log-transformed data were analyzed if a Kolmogorov-Smirnov test rejected normality but original data were reported for the sake of clarity. The Levene's and Box's tests failed to reject homogeneity of variances and covariance matrices, respectively.

A 2 (INT vs. CG) $\times 2$ (baseline and after six weeks) mixed-model ANOVA evaluated the intervention effects on the FMS test outcomes, and a group-by-time interaction effect (a $2 \times 2$ interaction effects) was the hypothesis of primary interest. We analyzed the simple main effects of time to show the mean changes in the FMS scores after six weeks for each group, and the six-week-induced changes are reported as percentage of change $(\% \Delta)$. Partial eta squared $\left(\right.$ partial $\left.\eta^{2}\right)$ is reported as a measure of an effect size for the interaction effects, and defined as small (0.01), medium (0.06), and large (0.14) [26]. Bonferroni adjusted $p$-values for multiple comparisons, and the level of significance was set at $p \leq 0.05$.

\section{Results}

After six weeks, the INT and CG mean performance significantly improved in six and five FMS component tests, respectively. Both groups also enhanced total FMS score after six weeks. However, the INT increased the mean performance of the hurdle step, in-line lunge, rotatory stability, and total FMS to a significantly greater extent as compared to the CG. For detailed results of the $2 \times 2$ mixed-design ANOVA model, see Table 2.

Table 2. The Functional Movement Screen (FMS) scores at pre- and post-test for the intervention and control group.

\begin{tabular}{|c|c|c|c|c|c|c|c|}
\hline \multirow{2}{*}{$\begin{array}{c}\text { Outcome } \\
\text { Group }\end{array}$} & \multirow{2}{*}{$\begin{array}{c}\text { Pre-Test } \\
\text { Mean } \pm \text { SD }\end{array}$} & \multirow{2}{*}{$\begin{array}{c}\text { Post-Test } \\
\text { Mean } \pm \text { SD }\end{array}$} & \multirow{2}{*}{$\% \Delta$} & \multicolumn{4}{|c|}{ A Group-by-Time Interaction Effect } \\
\hline & & & & $F_{(1,136)}$ & $p$ & Partial $\eta^{2}$ & $1-\beta$ \\
\hline \multicolumn{8}{|c|}{ Deep Squat (score) } \\
\hline INT & $2.32 \pm 0.57$ & $2.52 \pm 0.50$ & $+8.6^{* *}$ & \multirow{2}{*}{0.51} & \multirow{2}{*}{0.48} & \multirow{2}{*}{0.00} & \multirow{2}{*}{0.11} \\
\hline CG & $2.32 \pm 0.64$ & $2.51 \pm 0.59$ & $+8.2 *$ & & & & \\
\hline \multicolumn{8}{|c|}{ Hurdle Step (score) } \\
\hline INT & $2.05 \pm 0.28$ & $2.32 \pm 0.50$ & $+13.2 * *$ & \multirow{2}{*}{5.48} & \multirow{2}{*}{0.02} & \multirow{2}{*}{0.04} & \multirow{2}{*}{0.64} \\
\hline CG & $2.08 \pm 0.32$ & $2.15 \pm 0.40$ & +3.4 & & & & \\
\hline \multicolumn{8}{|c|}{ In-line Lunge (score) } \\
\hline INT & $2.18 \pm 0.54$ & $2.56 \pm 0.53$ & $+17.4^{* *}$ & \multirow{2}{*}{3.77} & \multirow{2}{*}{0.05} & \multirow{2}{*}{0.03} & \multirow{2}{*}{0.49} \\
\hline CG & $2.22 \pm 0.57$ & $2.40 \pm 0.58$ & $+8.1 *$ & & & & \\
\hline \multicolumn{8}{|c|}{ Shoulder Mobility (score) } \\
\hline INT & $2.84 \pm 0.37$ & $2.89 \pm 0.31$ & +1.8 & \multirow{2}{*}{2.27} & \multirow{2}{*}{0.14} & \multirow{2}{*}{0.02} & \multirow{2}{*}{0.32} \\
\hline CG & $2.48 \pm 0.64$ & $2.63 \pm 0.51$ & $+5.7^{* *}$ & & & & \\
\hline \multicolumn{8}{|c|}{ Active Straight Leg Raise (score) } \\
\hline INT & $2.49 \pm 0.60$ & $2.68 \pm 0.49$ & $+7.6^{*}$ & \multirow{2}{*}{1.29} & \multirow[b]{2}{*}{0.23} & \multirow[b]{2}{*}{0.01} & \multirow[b]{2}{*}{0.20} \\
\hline CG & $2.51 \pm 0.64$ & $2.80 \pm 0.40$ & $+10.4^{* *}$ & & & & \\
\hline \multicolumn{8}{|c|}{ Trunk Stability Push Up (score) } \\
\hline INT & $2.63 \pm 0.49$ & $2.89 \pm 0.32$ & $+9.9^{* *}$ & \multirow{2}{*}{3.25} & & & \\
\hline CG & $2.71 \pm 0.49$ & $2.83 \pm 0.38$ & +4.4 * & & 0.07 & 0.02 & 0.43 \\
\hline Rotatory St & ility (score) & & & & & & \\
\hline INT & $1.96 \pm 0.20$ & $2.15 \pm 0.36$ & $+9.7^{* *}$ & & & & \\
\hline CG & $1.98 \pm 0.33$ & $2.03 \pm 0.17$ & +2.5 & 6.13 & 0.02 & 0.04 & 0.69 \\
\hline Total FMS & ore) & & & & & & \\
\hline INT & $16.45 \pm 1.27$ & $18.01 \pm 1.57$ & $+9.5^{* *}$ & & & & \\
\hline CG & $16.31 \pm 1.51$ & $17.43 \pm 1.47$ & $+6.9^{* *}$ & 4.18 & 0.04 & 0.03 & 0.53 \\
\hline
\end{tabular}

Values are Mean \pm SD; Abbreviations: INT intervention group; CG control group; $\% \Delta$ percentage of change from pre- to post-test; $\mathrm{F}$ (dffactor, dferror) = F-statistic; p probability value; partial $\eta^{2}$ partial eta squared; ${ }^{* *}$ significant changes after six weeks at $p<0.001$; * significant changes after six weeks at $p \leq 0.05$. 


\section{Discussion}

There is currently very little evidence of the ability to change scores on the FMS following a core strength training program. Accordingly, this study aimed to examine the effects of core strength training on FMS scores in university students. The results of this study showed that both groups improved significantly in the overall score on FMS. Previous research indicates that the average FMS scores are highest within the 20-39 age group (mean: 15.08), and lowest for those who were age 65 years (12.68) [20]. At pre-test, participants in our study had higher values for the total FMS score (mean \pm SD: intervention group $16.49 \pm 1.28$, control group $16.29 \pm 1.52$ ) compared to those norms. Therefore, it can be speculated that improvements would be even better with lower initial values for FMS.

Individually analyzing variables, the positive effects of the intervention are visible in the tests: hurdle step $\left(\eta_{\mathrm{p}}{ }^{2}=0.04\right)$, in-line lunge $\left(\eta_{\mathrm{p}}{ }^{2}=0.03\right)$, rotatory stability $\left(\eta_{\mathrm{p}}{ }^{2}=0.04\right)$, total FMS $\left(\eta_{\mathrm{p}}{ }^{2}=0.03\right)$. Core stability is of great importance in all three individual tests. In the hurdle step and in-line lunge tests, the support is on the standing leg while the movements are performed at the hip, knee and ankle. On that occasion, the fixators play an important role in order to stay upright without losing balance. It is similar when performing the rotator stability test. The FMS is used to evaluate performance with fundamental movements and to find deficits in the body during dynamic movements $[7,22]$. Accordingly, the core becomes activated before gross body movements as part of the postural control system $[16,27]$. The current study used a variety of core-stabilization training methods that included muscle endurance exercises, exercise using unstable surfaces, and performing some exercises in a weightbearing position, which may be the reason why scores in the FMS improved.

In summary, the main idea was to develop core stability throughout core muscle isometric strengthening, because ideal quality of core stabilization is a foundation for any proper movement, and then progress to dynamic stability exercises by incorporating limb movements and changing positions [16]. In general, the core stability affects the effective use of the strength and endurance required [28].

This study supports the use of exercise interventions in university students for the improvement in the FMS score. There is sufficient evidence for the effectiveness of core stability training in untrained individuals. Functional movement screen test results showed greater change for the exercise group compared with the control group. This result justifies the hypothesis that core strengthening can improve FMS in college students even with short duration programs. Similar results were obtained by applying a periodized functional strength training program to the total FMS score in college students of physical education [29].

We had some limitations, of which the most important could be listed as the nonexistence of randomization. The study did not include effects on other motor skills. High baseline values also significantly contributed to a smaller effect size in our study.

\section{Conclusions}

Relative to research findings, it is safe to infer that FMS could be used for the assessment of changes in movement pattern induced by six-week core-stabilization-training. Isometric core strengthening with an exercise program involving multiplane movements has plausible benefits to functional movement patterns. Practitioners working in this population should consider the specific changes in the intervention group in this study. It would be interesting for future studies to consider the long-term effects of core strengthening program, as well as the application of programs for people with existing pain syndromes. 
Author Contributions: Conceptualization, T.Š. and B.P.-G.; methodology, N.T.; software, D.M.; validation, G.S., T.R. and Z.M.; formal analysis, D.M.; investigation, T.Š.; resources, B.P.-G.; data curation, T.Š.; writing-original draft preparation, T.Š.; writing-review and editing T.Š.; visualization, K.L.; supervision, D.M.M.; project administration, N.T.; funding acquisition, G.S., T.R. and D.M.M. All authors have read and agreed to the published version of the manuscript.

Funding: This research received no external funding.

Conflicts of Interest: The authors declare no conflict of interest.

\section{References}

1. Taanila, H.; Suni, J.H.; Kannus, P.; Pihlajamäki, H.; Ruohola, J.-P.; Viskari, J.; Parkkari, J. Risk factors of acute and overuse musculoskeletal injuries among young conscripts: A population-based cohort study. BMC Musculoskelet. Disord. 2015, 16, 104. [CrossRef] [PubMed]

2. Poček, S.; Trivić, T.; Roklicer, R.; Ostojić, S.M.; Drid, P. Long-term outcomes of sports on health status: A mini review. EQOL J. 2018, 10, 5-15. [CrossRef]

3. Parkkari, J.; Kannus, P.; Natri, A.; Lapinleimu, I.; Palvanen, M.; Heiskanen, M.; Vuori, I.; Järvinen, M. Active living and injury risk. Int. J. Sports Med. 2004, 25, 209-216. [PubMed]

4. Tiirikainen, K.; Lounamaa, A.; Paavola, M.; Kumpula, H.; Parkkari, J. Trend in sports injuries among young people in Finland. Int. J. Sports Med. 2008, 29, 529-536. [CrossRef] [PubMed]

5. Dorrel, B.S.; Long, T.; Shaffer, S.; Myer, G.D. Evaluation of the functional movement screen as an injury prediction tool among active adult populations: A systematic review and meta-analysis. Sports Health 2015, 7, 532-537. [CrossRef] [PubMed]

6. Kiesel, K.; Plisky, P.; Butler, R. Functional movement test scores improve following a standardized off-season intervention program in professional football players. Scand. J. Med. Sci. Sports 2011, 21, 287-292. [CrossRef]

7. Cook, G.; Burton, L.; Hoogenboom, B. Pre-Participation screening: The use of fundamental movements as an assessment of function-Part 2. N. Am. J. Sports Phys. Ther. 2006, 1, 132-139.

8. Wright, M.D.; Portas, M.D.; Evans, V.J.; Weston, M. The effectiveness of 4 weeks of fundamental movement training on functional movement screen and physiological performance in physically active children. J. Strength Cond. Res. 2015, 29, 254-261. [CrossRef]

9. Frost, D.M.; Beach, T.A.; Callaghan, J.P.; McGill, S.M. Using the functional movement screen ${ }^{\mathrm{TM}}$ to evaluate the effectiveness of training. J. Strength Cond. Res. 2012, 26, 1620-1630. [CrossRef]

10. Inder, J.D.; Carlson, D.J.; Dieberg, G.; McFarlane, J.R.; Hess, N.C.; Smart, N.A. Isometric exercise training for blood pressure management: A systematic review and meta-analysis to optimize benefit. Hypertens. Res. 2016, 39, 88-94. [CrossRef]

11. Cowen, V.S. Functional fitness improvements after a worksite-based yoga initiative. J. Bodyw. Mov. Ther. 2010, 14, 50-54. [CrossRef] [PubMed]

12. Goss, D.L.; Christopher, G.E.; Faulk, R.T.; Moore, J. Functional training program bridges rehabilitation and return to duty. J. Spec. Oper. Med. 2009, 9, 29-48. [PubMed]

13. Panjabi, M.M. The stabilizing system of the spine. Part I. Function, dysfunction, adaptation, and enhancement. J. Spinal Disord. 1992, 5, 383-389. [CrossRef] [PubMed]

14. Bendjaballah, M.Z.; Shirazi-Adl, A.; Zukor, D.J. Finite element analysis of human knee joint in varus-valgus. Clin. Biomech. (Bristol Avon) 1997, 12, 139-148. [CrossRef]

15. Hewett, T.E.; Zazulak, B.T.; Myer, G.D.; Ford, K.R. A review of electromyographic activation levels, timing differences, and increased anterior cruciate ligament injury incidence in female athletes. Br. J. Sports Med. 2005, 39, 347-350. [CrossRef] [PubMed]

16. Davidek, P.; Andel, R.; Kobesova, A. Influence of dynamic neuromuscular stabilization approach on maximum kayak paddling force. J. Hum. Kinet 2018, 61, 15-27. [CrossRef]

17. Çelenay, Ş.T.; Kaya, D.Ö. An 8-week thoracic spine stabilization exercise program improves postural back pain, spine alignment, postural sway, and core endurance in university students: A randomized controlled study. Turk. J. Med. Sci. 2017, 47, 504-513. [CrossRef]

18. Carter, J.M.; Beam, W.C.; McMahan, S.G.; Barr, M.L.; Brown, L.E. The effects of stability ball training on spinal stability in sedentary individuals. J. Strength Cond. Res. 2006, 20, 429-435. 
19. Callaghan, J.P.; Gregory, D.E.; Durkin, J.L. Do nirs measures relate to subjective low back discomfort during sedentary tasks? Int. J. Ind. Ergon. 2010, 40, 165-170. [CrossRef]

20. Perry, F.T.; Koehle, M.S. Normative data for the functional movement screen in middle-aged adults. J. Strength Cond. Res. 2013, 27, 458-462. [CrossRef]

21. Farrell, S.W.; Pavlovic, A.; Barlow, C.E.; Leonard, D.; DeFina, J.R.; Willis, B.L.; DeFina, L.F.; Haskell, W.L. Functional movement screening performance and association with key health markers in older adults. J. Strength Cond. Res. 2019. [CrossRef] [PubMed]

22. Cook, G.; Burton, L.; Hoogenboom, B. Pre-participation screening: The use of fundamental movements as an assessment of function-Part 1. N. Am. J. Sports. Phys. Ther. 2006, 1, 62-72. [PubMed]

23. Minick, K.I.; Kiesel, K.B.; Burton, L.; Taylor, A.; Plisky, P.; Butler, R.J. Interrater reliability of the functional movement screen. J. Strength Cond. Res. 2010, 24, 479-486. [CrossRef]

24. Teyhen, D.S.; Shaffer, S.W.; Lorenson, C.L.; Halfpap, J.P.; Donofry, D.F.; Walker, M.J.; Dugan, J.L.; Childs, J.D. The functional movement screen: A reliability study. J. Orthop. Sports Phys. Ther. 2012, 42, 530-540. [CrossRef] [PubMed]

25. McGill, S.M.; Karpowicz, A. Exercises for spine stabilization: Motion/motor patterns, stability progressions, and clinical technique. Arch. Phys. Med. Rehabil. 2009, 90, 118-126. [CrossRef]

26. Lakens, D. Calculating and reporting effect sizes to facilitate cumulative science: A practical primer for T-tests and anovas. Front. Psychol. 2013, 4, 863. [CrossRef]

27. Sandrey, M.A.; Mitzel, J.G. Improvement in dynamic balance and core endurance after a 6-week core-stability-training program in high school track and field athletes. J. Sport Rehabil. 2013, 22, $264-271$. [CrossRef]

28. Chang, N.-J.; Tsai, I.; Lee, C.-L.; Liang, C.-H. Effect of a six-week core conditioning as a warm-up exercise in physical education classes on physical fitness, movement capability, and balance in school-aged children. Int. J. Environ. Res. Public Health 2020, 17, 5517. [CrossRef]

29. Sawczyn, M. Effects of a periodized Functional Strength Training program (FST) on Functional Movement Screen (FMS) in physical education students. Phys. Educ. Stud. 2020, 24, 162-167. [CrossRef]

Publisher's Note: MDPI stays neutral with regard to jurisdictional claims in published maps and institutional affiliations.

(C) 2020 by the authors. Licensee MDPI, Basel, Switzerland. This article is an open access article distributed under the terms and conditions of the Creative Commons Attribution (CC BY) license (http://creativecommons.org/licenses/by/4.0/). 